\title{
Isolation of a Bimetallic Cobalt(III) Nitride and Examination of Its Hydrogen Atom Abstraction Chemistry and Reactivity Towards $\mathrm{H}_{2}$
}

\author{
Debabrata Sengupta, ${ }^{\dagger}$ Christian Sandoval-Pauker, ${ }^{\ddagger}$ Emily Schueller, ${ }^{\#}$ Angela Marisol Encerrado- \\ Manriquez, ${ }^{\dagger}$ Alejandro Metta-Magaña, ${ }^{\dagger}$ Wen-Yee Lee, ${ }^{\dagger}$ Ram Seshadri, ${ }^{\#, \Delta}$ Balazs Pinter, ${ }^{*}$, and Skye \\ Fortier*, ${ }^{*}$ \\ Department of Chemistry and Biochemistry, University of Texas at El Paso, El Paso, Texas 79968, United States \\ *Department of Chemistry, Universidad Técnica Federico Santa María, Valparaíso, 2390123, Chile \\ "Materials Department and Materials Research Laboratory, University of California, Santa Barbara, California 93106, United \\ States \\ ${ }^{\Delta}$ Department of Chemistry and Biochemistry, University of California, Santa Barbara, California 93106, United States
}

\begin{abstract}
Room temperature photolysis of the bis(azide)cobaltate(II) complex $\left[\mathrm{Na}(\mathrm{THF})_{\mathrm{x}}\right]\left[{ }^{\mathrm{ket}}\right.$ guan) $\left.\mathrm{Co}\left(\mathrm{N}_{3}\right)_{2}\right]$ (ketguan $\left.=\left[{ }^{t} \mathrm{Bu}_{2} \mathrm{CN}\right) \mathrm{C}(\mathrm{NDipp})_{2}\right]^{-}$, Dipp $=2,6$-diisopropylphenyl $) \quad(\mathbf{3 a})$ in THF cleanly forms the binuclear cobalt nitride $\left[\mathrm{Na}(\mathrm{THF})_{4}\left\{\left[\left({ }^{\mathrm{ket}} \text { guan }\right) \mathrm{Co}\left(\mathrm{N}_{3}\right)\right]_{2}(\mu-\mathrm{N})\right\}\right]_{\mathrm{n}}(\mathbf{1})$. Compound 1 represents the first example of an isolable, bimetallic cobalt nitride complex, and it has been fully characterized by spectroscopic, magnetic, and computational analyses. Density functional theory supports a $\mathrm{Co}^{\mathrm{III}}=\mathrm{N}=\mathrm{Co}^{\mathrm{III}}$ canonical form with significant $\pi$-bonding between the cobalt centers and the nitride atom. Unlike other Group 9 bridging nitride complexes, no radical character is detected at the bridg-

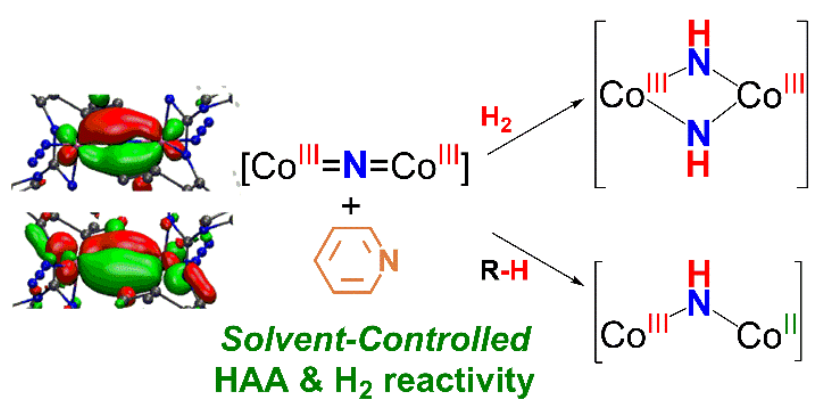
ing $\mathrm{N}$-atom of $\mathbf{1}$. Indeed, $\mathbf{1}$ is unreactive towards weak $\mathrm{C}-\mathrm{H}$ donors and even co-crystallizes with a molecule of cyclohexadiene (CHD) in its crystallographic unit cell to give $\mathbf{1}$. CHD as a room temperature stable product. Notably, addition of pyridine to $\mathbf{1}$ or photolyzed solutions of $\left[\left({ }^{\mathrm{ket}} \text { guan }\right) \mathrm{Co}\left(\mathrm{N}_{3}\right)(\mathrm{py})\right]_{2}(\mathbf{4 a})$ leads to destabilization via activation of the nitride unit, resulting in the mixedvalent $\mathrm{Co}(\mathrm{II}) /(\mathrm{III})$ bridged imido species $\left[{ }^{\mathrm{ket}}\right.$ guan $) \mathrm{Co}_{2}(\mu-\mathrm{NH})\left(\mu-\mathrm{N}_{3}\right)(\mathbf{5})$ formed from intermolecular hydrogen atom abstraction (HAA) of strong $\mathrm{C}-\mathrm{H}$ bonds (BDE $\sim 100 \mathrm{kcal} / \mathrm{mol}$ ). Kinetic rate analysis of the formation of 5 in the presence of $\mathrm{C}_{6} \mathrm{H}_{12}$ or $\mathrm{C}_{6} \mathrm{D}_{12}$ gives a KIE $=2.5 \pm 0.1$, supportive of a HAA formation pathway. The reactivity of our system was further probed by photolyzing $\mathrm{C}_{6} \mathrm{D}_{6} / \mathrm{py}-d_{5}$ solutions of $\mathbf{4 a}$ under an $\mathrm{H}_{2}$ atmosphere (150 psi), which leads to the exclusive formation of the bis(imido) [( ${ }^{\mathrm{ket}-}$ guan $) \mathrm{Co}(\mu-\mathrm{NH})]_{2}(\mathbf{6})$ as a result of dihydrogen activation. These results provide unique insights into the chemistry and electronic structure of late $3 \mathrm{~d}$-metal nitrides while providing entryway into $\mathrm{C}-\mathrm{H}$ activation pathways.
\end{abstract}

\section{INTRODUCTION}

Complexes containing metal-ligand multiple bonds, both biological and synthetic, have been intensively investigated owing to the participation of these moieties in a host of important reactions including $\mathrm{C}-\mathrm{H}$ bond activation, ${ }^{1}$ olefin metathesis, ${ }^{2}$ cycloaddition, ${ }^{3}$ and heteroatom transfer reactivity. ${ }^{4}$ Indeed, the $\mathrm{Fe}=\mathrm{O}$ intermediate formed in the active site of cytochrome P450 is critical for its enzymatic versatility. ${ }^{5}$ Of note, isolable compounds containing $\mathrm{M}=\mathrm{E}$ or $\mathrm{M} \equiv \mathrm{E}$ bonds have been dominated by the early to mid-transition metals, while the synthesis and isolation of late metal complexes presents a more significant challenge due to the progressive population of $\mathrm{M}=\mathrm{E} / \mathrm{M} \equiv \mathrm{E} \pi^{*}$-orbitals, leading to high reactivity and instability. $^{6-8}$

In specific regard to Group $9-11$ metals in tetragonal ligand fields, it is considered the case that $d$-orbital occupation with electron counts of $n \geq 4$ is incompatible with metal-ligand multiple bonds, a concept that has been coined the "oxo wall."5, 9-10 Yet, the oxo wall can be circumvented through lowering the coordination number and symmetry, employing sterically encumbering ligands, ${ }^{7}, 11-12$ and reducing the $d$ electron count through metal oxidation. ${ }^{6,8,13}$ These strategies have been effective for a handful of $\mathrm{Rh} / \mathrm{Ir}$ compounds such as the iridium(V)oxo $\operatorname{Ir}(\mathrm{O})(\mathrm{mes})_{3}$ (mes = mesityl) synthesized by Wilkinson, ${ }^{14}$ and nitride species such as (PNP)Ir(N) $(\mathrm{PNP}=$ $\left.\mathrm{N}\left(\mathrm{CHCHP}^{t} \mathrm{Bu}_{2}\right)_{2}\right)$ reported by the groups of de Bruin and Schneider, ${ }^{8}$ amongst others. ${ }^{15-19}$ However, this can lead to nontrivial canonical forms, which complicates electronic structure interpretations and formal oxidation state assignments. ${ }^{8,20}$

Extension of these synthetic strategies to cobalt has afforded a number of imido-complexes ${ }^{13}$ and recently led to the isolation and structural characterization of the first terminal cobalt(III)-oxo species $\left[\mathrm{PhB}\left({ }^{t} \mathrm{BuIm}\right)_{3}\right] \mathrm{Co}(\mathrm{O})$ ( $\mathrm{Im}=$ imidazol-2ylidene) ${ }^{21}$ Notably, though, terminal cobalt-nitrides still remain elusive. In 2010, Chirik et al. reported that thermolysis or photolysis of $\left({ }^{\mathrm{iPr}} \mathrm{PDI}\right) \mathrm{CoN}_{3}$ ( ${ }^{\mathrm{iPr}} \mathrm{PDI}=2,6-\left(2,6-{ }^{i} \mathrm{Pr}_{2}-\mathrm{C}_{6} \mathrm{H}_{3}-\right.$ 

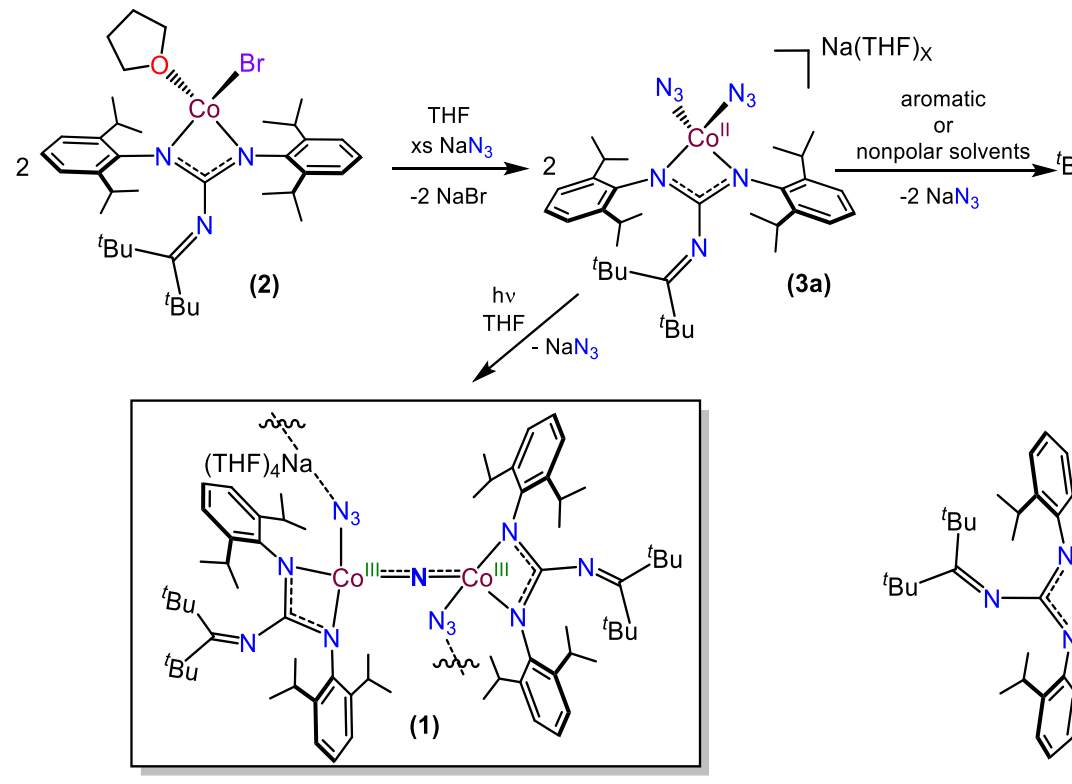

(3b)<smiles>CC(=NC(C)C)N=C(c1c(C(C)C)cccc1C(C)C)N(C)c1c(C(C)C)cccc1C(C)C</smiles>

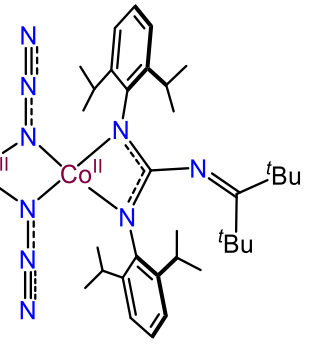
$\mathrm{C}_{6} \mathrm{H}_{6} /$ pyridine $(10: 1)$
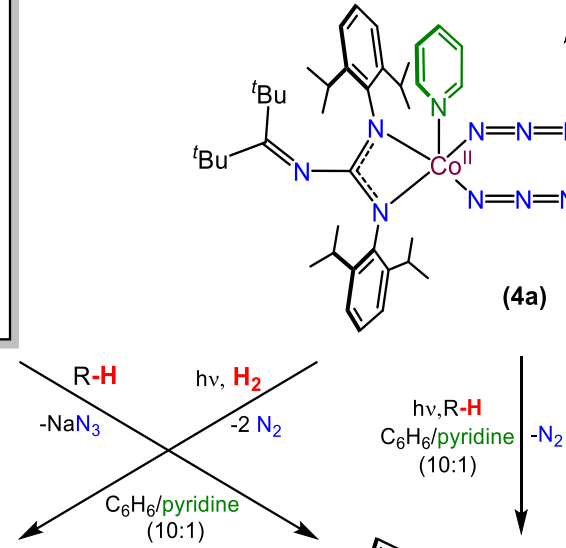

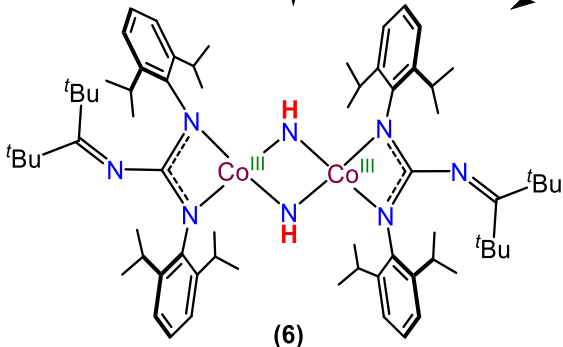

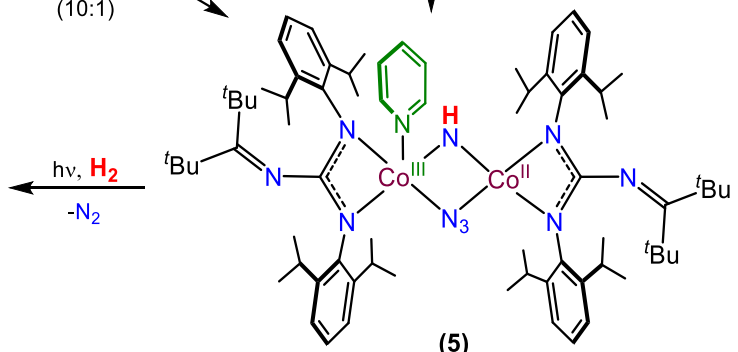

Scheme 1. Synthetic overview and HAA reactivity with alkanes and $\mathrm{H}_{2}$.

$\mathrm{N}=\mathrm{CMe})_{2} \mathrm{C}_{5} \mathrm{H}_{3} \mathrm{~N}$ ) leads to intramolecular $N$-atom insertion, attributed to the formation of a fleeting terminal cobalt nitride. $^{22}$ Later, Meyer and co-workers were able to trap an intermediate nitride complex through the use of the $\operatorname{bis}(\mathrm{N}$ heterocyclic carbene)-mono(phenolate) chelated compound $\left(\mathrm{BIMPN}^{\mathrm{Mes}, \mathrm{Ad}, \mathrm{Me}}\right) \mathrm{Co}(\mathrm{N})$ at $10 \mathrm{~K}$, which upon warming undergoes $\mathrm{N}$-atom insertion into a Co-C bond. ${ }^{23}$ Consequently, controlled reactivity studies of the cobalt-nitride moiety remain unknown.

It has come to light in recent years that the lifetime of $\mathrm{Co}=\mathrm{O}$ complexes can be extended through the coordination of redox-inactive Lewis acids to the oxo moiety. ${ }^{24}$ These compounds are still short-lived, but under this cooperative model, the second metal can alleviate charge density that would otherwise occupy antibonding orbitals, thereby extending lifetimes. Notably, Tomson and co-workers have capitalized upon this strategy utilizing macrocyclic pyridyl-diimine ligands to generate the putative dinuclear cobalt nitride $\left[\left({ }^{n} \mathrm{PDI}_{2}\right) \mathrm{Co}_{2}(\mu\right.$ $\left.\mathrm{N})\left(\mathrm{PMe}_{3}\right)_{2}\right]^{3+}{ }^{25}$ This nitride is not observed but its formation is indicated through the isolation of phosphinimide and intramolecular C-H amination products formed as the result of passing Co-N-Co formation. Building upon this approach of utilizing bimetallic systems to stabilize Group 9 metal-ligand multiple bonds, we have targeted the synthesis of isolable homobimetallic bridging $\mathrm{Co}=\mathrm{N}=\mathrm{Co}$ complexes through steric and geo- metric control to gain access and insight into elusive cobaltnitride bonds.

As part of our ongoing effort to utilize bulky guanidinate ligands to stabilize $3 \mathrm{~d}$-metal complexes with rare and reactive bonding motifs, ${ }^{26-27}$ herein, we demonstrate the isolation and the reactivity studies of a mid-valent, four-coordinate, bimetallic $\quad \mathrm{Co}(\mathrm{III})$-nitride complex, namely $\left\{\left[\mathrm{Na}(\mathrm{THF})_{4}\right]\left[\left({ }^{\mathrm{ket}} \text { guan }\right) \mathrm{Co}(\mu-\mathrm{N})\left(\mathrm{N}_{3}\right)\right]_{2}\right\}_{\mathrm{n}} \quad$ (1) $\quad\left({ }^{\mathrm{ket}}\right.$ guan $=$ $\left({ }^{t} \mathrm{Bu}_{2} \mathrm{CN}\right) \mathrm{C}(\mathrm{NDipp})_{2}$, Dipp = 2,6-diisopropylphenyl). While 1 is stable as a solid and in solution, chemical activation of the nitride moiety can be achieved by perturbation of the ligand field through a coordination switch attained by simple addition of pyridine, resulting in intermolecular hydrogen atom abstraction (HAA) chemistry. Impressively, 1 can perform HAA on strong, unactivated $\mathrm{C}-\mathrm{H}$ bonds $(\mathrm{BDE} \sim 100 \mathrm{kcal} / \mathrm{mol})$, generating the parent-imido, mixed-valent complex $\left[\left({ }^{\mathrm{ket}} \text { guan }\right) \mathrm{Co}\right]_{2}(\mu-$ $\mathrm{NH})\left(\mu-\mathrm{N}_{3}\right)(\mathbf{5})$. Moreover, 1 is reactive towards dihydrogen, cleaving the $\mathrm{H}_{2}$ bond (BDE $105 \mathrm{kcal} / \mathrm{mol}$ ) to give the bis(imido) $\left[\left({ }^{\mathrm{ket}} \text { guan }\right) \mathrm{Co}^{\mathrm{III}}(\mu-\mathrm{NH})\right]_{2}(\mathbf{6})$.

The combined stability of $\mathbf{1}$ and its solvent-triggered nitride activation provides a unique platform and opportunity to study the chemistry of cobalt-nitrides and multiply bonded late $3 \mathrm{~d}$ metal complexes that lie beyond the oxo wall. 
a.
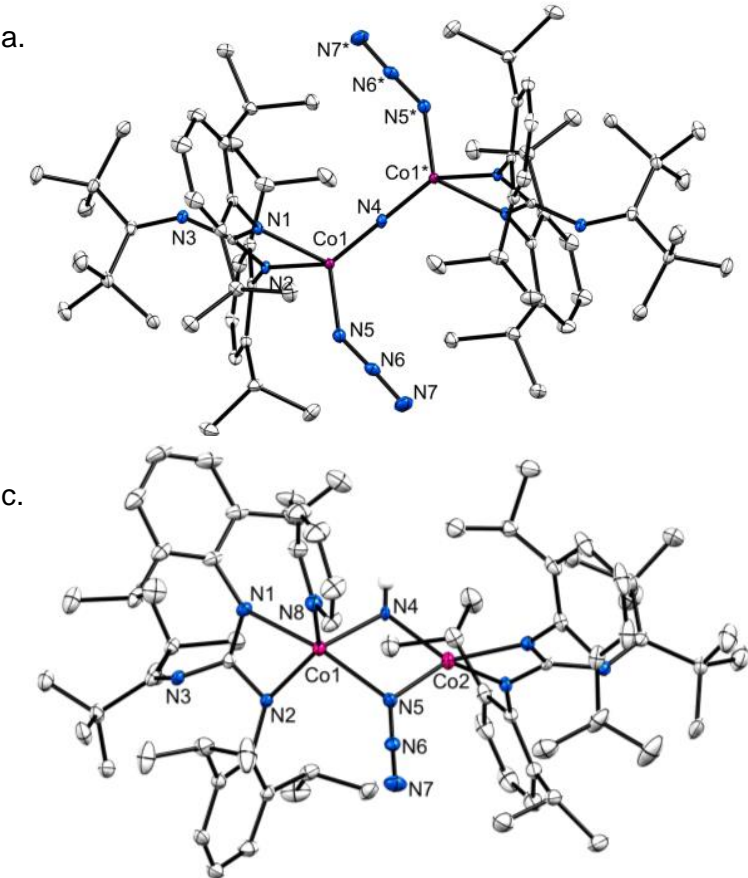

b.
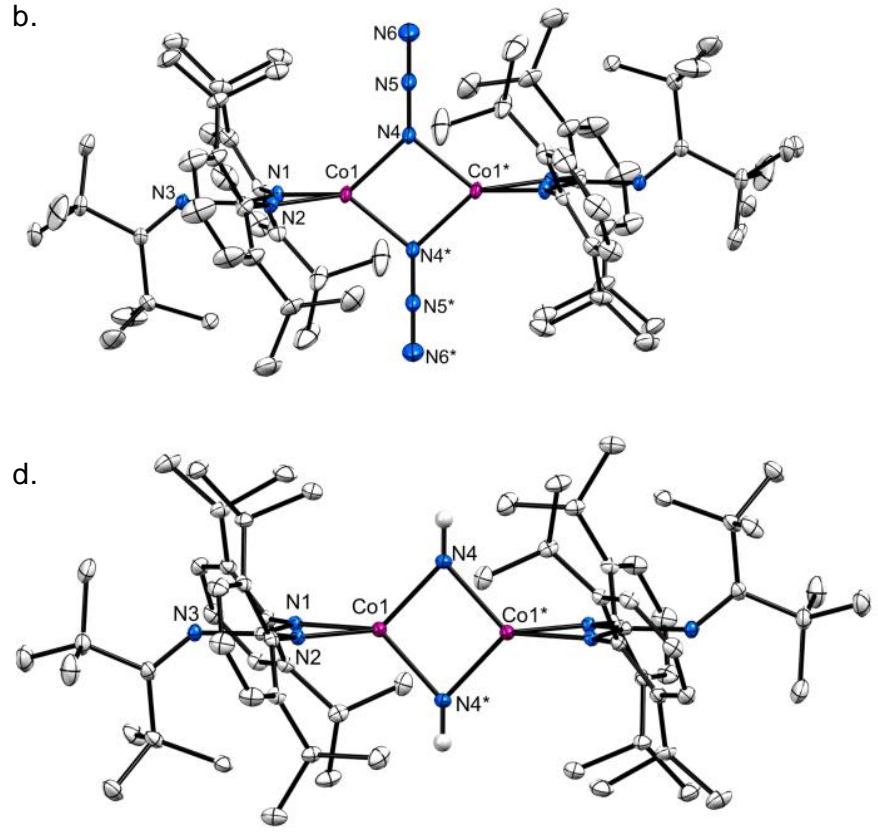

Figure 1. ORTEP representation of compounds (a) $1 \cdot \mathrm{CHD}$ (b) $3 \mathbf{b} \cdot \mathrm{THF}$ (c) $\mathbf{5} \cdot \mathrm{C}_{6} \mathrm{H}_{14}$ and (d) $\mathbf{6} \cdot 2 \mathrm{C}_{6} \mathrm{H}_{14} \cdot 2 \mathrm{C}_{5} \mathrm{H}_{12}$ with $30 \%$ probability ellipsoids. The $\left[\mathrm{Na}(\mathrm{THF})_{4}\right]^{+}$cation of $\mathbf{1}$, the hydrogen atoms (exception $\mathrm{N}-\mathrm{H}$ of $\mathbf{5}$ and $\mathbf{6}$ ), and co-crystallized solvents are omitted for clarity. Asterisks denote symmetry generated atoms.

\section{RESULTS AND DISCUSSION}

Synthesis and Characterization. Addition of $\mathrm{K}\left[{ }^{\mathrm{ket}}\right.$ guan] to $\mathrm{CoBr}_{2}(\mathrm{DME})$ in THF affords monomeric (ketguan) $\mathrm{Co}(\mathrm{Br})(\mathrm{THF})(\mathbf{2})$ which is readily converted to the cobal-

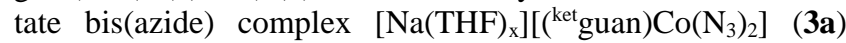
upon treatment with excess $\mathrm{NaN}_{3}$ in THF (Scheme 1). Upon dissolution in aromatic or non-polar solvents, the $\mathrm{NaN}_{3}$ is rapidly loss to give the neutral dimer $\left[{ }^{\mathrm{ket}}\right.$ guan $\left.) \mathrm{Co}\left(\mathrm{N}_{3}\right)\right]_{2}(\mathbf{3 b})$ (Scheme 1). As clearly observed through ${ }^{1} \mathrm{H}$ NMR spectroscopy, $\mathbf{2} \mathbf{- 3}$ are paramagnetic complexes (Figures S8 - S10). While pristine samples of $\mathbf{3 a}$ are complicated by the facile loss of $\mathrm{NaN}_{3}$, SQUID magnetometry measurements on solid-state samples of $\mathbf{3 b}$ reveal a room temperature effective magnetic moment of $7.3 \mu \mathrm{B}$ (Figure S20). This value is slightly higher than expected for the spin-only value for two non-interacting high spin $\mathrm{Co}(\mathrm{II})$ centers $(5.48 \mu \mathrm{B})$ but not beyond the range typically encountered for systems with high magnetic anisotropies. ${ }^{28-29}$

Compound $\mathbf{2}$ is isolated as a dark blue material, whereas $\mathbf{3 a}$ and $\mathbf{3 b}$ are green solids, all air-sensitive but stable indefinitely under dinitrogen atmosphere. Complex 3a is primarily stable to $\mathrm{NaN}_{3}$ loss in THF solution, but typically gives mixtures of $\mathbf{3 a}$ and $\mathbf{3 b}$ upon attempted isolation in the solid state. Regardless, the presence of $\mathbf{3 a}$ in solution is easily detected as it is spectroscopically distinct from $\mathbf{3 b}$ as indicated by NMR and UV-vis spectroscopies.

Single crystals of $\mathbf{3 b}$ can be grown from a saturated THF/hexanes (1:1) solution stored at $-30{ }^{\circ} \mathrm{C}$ for one day. Xray diffraction analysis of $\mathbf{3 b}$ confirms the formation of fourcoordinate, diamond core cobalt center (Figure 1b). The molecule crystallizes in the $P 2_{1} / c$ space group and contains onehalf of the dimer in the asymmetric unit which generates the full molecule through inversion symmetry. The bond metrics of 3b $(\mathrm{Co} 1-\mathrm{N} 1=1.994(2) \AA, \mathrm{Co} 1-\mathrm{N} 2=1.988(2) \AA, \mathrm{Co} 1-\mathrm{N} 4=$ $1.997(2) \AA)$ are comparable to those found in the related dinuclear cobalt complex $\left\{\left[\left({ }^{i} \mathrm{Pr}_{2} \mathrm{~N}\right) \mathrm{C}(\mathrm{NDipp})_{2}\right] \mathrm{Co}\left(\mu-\mathrm{N}_{3}\right)\right\}_{2}(\mathrm{Co}-\mathrm{N}=$ 1.991(3) - 1.994(3) $\AA$, Co-N $\left.\mathrm{N}_{\text {azide }}=2.010(3) \AA\right) .{ }^{30}$ Inspection of the azide units in $\mathbf{3 b}$ reveals inequivalent $\mathrm{N}-\mathrm{N}$ distances $(\mathrm{N} 4-\mathrm{N} 5=1.227(3) \AA$, N5-N6 = 1.135(4) $\AA$ ) consistent with azide activation, ${ }^{31}$ a feature also present in $\left\{\left[\left({ }^{i} \operatorname{Pr}_{2} \mathrm{~N}\right) \mathrm{C}(\mathrm{NDipp})_{2}\right] \mathrm{Co}\left(\mu-\mathrm{N}_{3}\right)\right\}_{2}$.

Based upon this observation, attempts were undertaken to initiate $\mathrm{N}_{2}$ loss to generate cobalt nitrides using $\mathbf{3 a}$ and $\mathbf{3 b}$. Room temperature photolysis ( $365 \mathrm{~nm}$ ) of THF solutions of 3a gradually gives way to the formation of a new paramagnetic species. The product is sparingly soluble and deposits as a crystalline solid from the photoreaction mixture. Surprisingly, single crystals suitable for X-ray diffraction analysis can be obtained through photolysis of $\mathbf{3 a}$ in THF solution containing excess 1,4-cyclohexadiene (CHD). The solid-state molecular structure revealed the formation of the dinuclear cobalt nitride 1. CHD (Scheme 1) co-crystallized with a molecule of CHD (Figures 1a and S1).

To the best of our knowledge, 1 represents the first example of a low nuclearity cobalt nitride complex as the closest related systems are nitride-encapsulated homo- and heterometallic clusters of the type $\left[\mathrm{Co}_{10} \mathrm{Rh}(\mathrm{N})_{2}(\mathrm{CO})_{21}\right]^{3-32}$ Compound 1. CHD crystallizes in the $P \overline{1}$ space group displaying one-half molecule in the asymmetric unit with the full dimer generated through inversion symmetry, and consequently, the Co1-N4$\mathrm{Co} 1 *$ bond angle is perfectly linear. Examination of the crystallographically unique cobalt-nitride distance $(\mathrm{Co} 1-\mathrm{N} 4=$ $1.678(1) \AA$ ) shows that it falls within the typical range of cobalt-imido

$\mathrm{Co}=\mathrm{NR}$

distances

(cf., 
$\left[\left({ }^{i} \mathrm{Pr}_{2} \mathrm{~N}\right) \mathrm{C}(\mathrm{NDipp})_{2}\right] \mathrm{Co}(=\mathrm{NAd}): \quad \mathrm{Co}-\mathrm{N}=1.621(3)$ $\left.\AA{ }^{30}\left[\left(\mathrm{TIMEN}^{\mathrm{aryl}}\right) \mathrm{Co}(=\mathrm{NAr})\right]\left(\mathrm{BPh}_{4}\right): \mathrm{Co}-\mathrm{N}=1.675(8) \AA{ }^{\mathrm{A}}\right){ }^{33}$

The metrical parameters of $\mathbf{1}$ are suggestive of a dimer with a core $\mathrm{Co}=\mathrm{N}=\mathrm{Co}$ unit. Yet, formal charge assignments can be complicated by a number of factors in molecules of this type. For example, the related $\mathrm{Rh}$ dimer $(\mathrm{PNN}) \mathrm{Rh}(\mathrm{N} \cdot) \mathrm{Rh}(\mathrm{PNN})$ (PNN = 6-di-(tert-butyl)phosphinomethylene-2,2'-bipyridine) is formulated as a $\mathrm{Rh}(\mathrm{II}) / \mathrm{Rh}(\mathrm{III})$ complex with a reactive, bridging nitridyl radical as discerned through electronic structure calculations. ${ }^{34}$ However, high electron delocalization obfuscates definitive oxidation state assignments, and the rhodium dimer may be more appropriately presented as $\left\{\mathrm{Rh}_{2} \mathrm{~N}\right\}^{13}$ utilizing Enemark-Feltham notation. In our case, the roomtemperature effective magnetic moment of 1 is $3.60 \mu_{\mathrm{B}}$ (Figure S19). Together with electronic structure analysis (vide infra), the data suggests the presence of two, high-spin Co(III) centers with partial antiferromagnetic coupling giving a total system spin of $S=2$. Thus, 1 can be formulated as possessing a $\mathrm{Co}^{\mathrm{III}}=\mathrm{N}=\mathrm{Co}^{\mathrm{III}}$ canonical form. In comparison to $\left\{\mathrm{Rh}_{2} \mathrm{~N}\right\}^{13}$ in $(\mathrm{PNN}) \mathrm{Rh}(\mathrm{N} \cdot) \mathrm{Rh}(\mathrm{PNN}), \mathbf{1}$ contains a $\left\{\mathrm{Co}_{2} \mathrm{~N}\right\}^{12}$ unit where the geometry and lower electron count aids in avoiding population of $\mathrm{Co}-\mathrm{N} \pi *$-orbitals (vide infra).

Betley et al. recently demonstrated that geometric perturbation of the three-coordinate $\mathrm{Co}(\mathrm{III})$ imido $\left({ }^{\text {dipy }} \mathrm{L}\right) \mathrm{Co}(\mathrm{NR})\left({ }^{\text {dipy }} \mathrm{L}\right.$ = 5-mesityl-1,9-(2,4,6- $\left.\mathrm{Ph}_{3} \mathrm{C}_{6} \mathrm{H}_{2}\right)$ dipyrrin) by pyridine ligation to give $\left.{ }^{\text {dipy }} \mathrm{L}\right) \mathrm{Co}(\mathrm{NR})(\mathrm{py})$ leads to ligand-accelerated $\mathrm{C}-\mathrm{H}$ bond amination. ${ }^{35}$ Enhanced reactivity towards $\mathrm{C}-\mathrm{H}$ bonds in the presence of pyridine with the (salen)ruthenium(VI)-nitrido complex $[($ salen $) \mathrm{Ru}(\mathrm{N})(\mathrm{MeOH})] \mathrm{PF}_{6}$ has also been reported. ${ }^{36}$ In either case, this promotion of reactivity is ascribed in part to the increased electronic saturation at the metal centers after pyridine coordination.

Investigating the role of pyridine coordination in our sys-

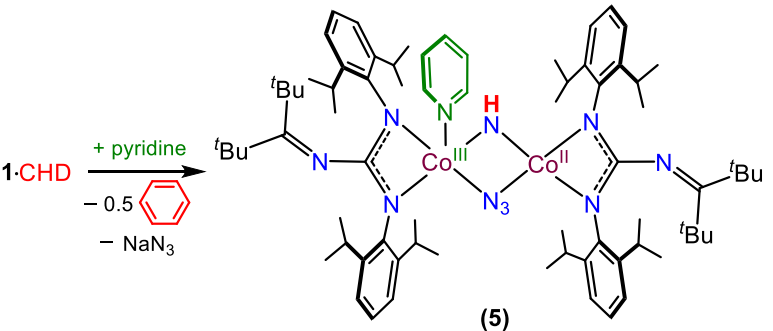

tem further, 3a was treated with a $\mathrm{C}_{6} \mathrm{H}_{6} /$ py (10:1) solution, which produces a mixture of the dimer $\left[\left({ }^{\mathrm{ket}} \text { guan }\right) \mathrm{Co}\left(\mathrm{N}_{3}\right)(\mathrm{py})\right]_{2}$ (4a) and the 2D-coordination polymer $\left\{\left[\mathrm{Na}(\mathrm{THF})_{2}\right]\left[\left({ }^{\mathrm{ket}} \text { guan }\right) \mathrm{Co}\left(\mathrm{N}_{3}\right)_{2}\right]\right\}_{n} \quad$ (4b) (Figures S4 and S5). Similar solubility properties complicate separation; however, 4a is selectively obtained from the addition of pyridine to benzene solution of $\mathbf{3 b}$ (Scheme 1). Of further note, the solidstate molecular structure of $\mathbf{4 a} \cdot \mathrm{THF} \cdot \mathrm{C}_{5} \mathrm{H}_{12}$ (Figure S4) shows azide rearrangement, adopting end-on coordination modes, with the cobalt centers in distorted square pyramidal geometries; yet, poor resolution of the diffraction data only permits a qualitative structural analysis of $4 \mathbf{a} \cdot \mathrm{THF} \cdot \mathrm{C}_{5} \mathrm{H}_{12}$, preventing assessment of azide N-N distances and their degree of activation.

Gratifyingly, addition of pyridine to $1 \cdot \mathrm{CHD}$ leads to the quantitative formation of the bimetallic bridging imido $\mathbf{5}$ where its $\mathrm{N}-\mathrm{H}$ proton is derived as the product of HAA from the co-crystallized CHD (eq 1). Accordingly, this reaction is accompanied by the formation of 0.5 equiv of benzene (Figure S27). As in the cases of ( $\left.{ }^{\text {dipy }} \mathrm{L}\right) \mathrm{Co}(\mathrm{NR})$ and [(salen) $\mathrm{Ru}(\mathrm{N})(\mathrm{MeOH})] \mathrm{PF}_{6}$, the coordination of pyridine to $\mathbf{1}$ acts as a solvent-switch, greatly enhancing the reactivity of the bridging nitride atom.

Furthermore, photolysis of $\mathbf{4 a}$ in $\mathrm{C}_{6} \mathrm{H}_{6} /$ py (10:1) solution also generates 5; though, when conducted in the absence of $\mathrm{H}$ atom donors such as CHD, the yield is considerably lower and is accompanied by substantial amounts of ${ }^{\mathrm{ket}}$ guanH.

Complex $\mathbf{5}$ is a dark brown, paramagnetic compound that is soluble in non-polar solvents. Single crystals of $\mathbf{5} \cdot \mathrm{C}_{6} \mathrm{H}_{14}$ are obtained from concentrated hexanes solution, and its solidstate molecular structure (Figure 1c) reveals an asymmetric, bimetallic complex with four- and five-coordinate cobalt centers possessing bridging $\mathrm{NH}$ and $\mathrm{N}_{3}$ groups. The cobalt-imido bond distances of $\mathbf{5} \cdot \mathrm{C}_{6} \mathrm{H}_{14}(\mathrm{Co} 1-\mathrm{N} 4=1.963(3) \AA$, Co2-N4 = $1.925(3) \AA$ ) are not informative as they fall within the range of both amido (cf., $\left\{\left[\left(\mathrm{NH}_{2} \mathrm{CH}_{2} \mathrm{CH}_{2} \mathrm{NH}_{2}\right)_{2} \mathrm{Co}\right]_{2}\left(\mu-\mathrm{NH}_{2}\right)(\mu\right.$ $\left.\mathrm{OH})\}\left[\mathrm{NO}_{3}\right]_{4}: \mathrm{Co}-\mathrm{N}=1.947(5)-1.948(5) \AA\right)^{37}$ and imidobridged cobalt compounds (cf., $\left\{[\mathrm{HC}(\mathrm{MeCNDipp})]_{2} \mathrm{Co}(\mu-\right.$ NAr) $\left.\}_{2}: \mathrm{Co}-\mathrm{N}=1.983(3)-1.988(3) \AA\right) .{ }^{38}$ On the other hand, SQUID magnetometry measurements of $\mathbf{5}$ give a roomtemperature effective magnetic moment of $3.97 \mu \mathrm{B}$, supportive of a mixed-valent system containing high-spin $\mathrm{Co}$ (II) $(S=1.5)$ and low-spin $\operatorname{Co}(\mathrm{III})(S=0)$.

Expanding upon the observed pyridine promoted HAA chemistry of 1 towards CHD, its reactivity with other hydrocarbons was studied. Interestingly, addition of pyridine to $\mathbf{1}$ or photolysis of $4 a$ in $\mathrm{C}_{6} \mathrm{H}_{6} /$ py in the presence of 9,10dihydroanthracene (DHA) (BDE: $76.3 \mathrm{kcal} / \mathrm{mol})^{39}$ fails to give anthracene. We presume this is a consequence of steric hindrance as the two hydrocarbon substrates possess comparably weak $\mathrm{C}-\mathrm{H}$ bonds (Figure 2a). Notably, $\mathrm{PhB}\left({ }^{t} \mathrm{BuIm}\right)_{3} \mathrm{Co}(\mathrm{O})$ is reactive towards $\mathrm{DHA}$, giving $\mathrm{PhB}\left({ }^{t} \mathrm{BuIm}\right)_{3} \mathrm{Co}(\mathrm{OH})$ and anthracene as products. ${ }^{21}$

Conversely, $\mathbf{1}$ is reactive in $\mathrm{C}_{6} \mathrm{H}_{6} /$ py solution towards several hydrocarbon substrates, including those with strong $\mathrm{C}-\mathrm{H}$ bonds, giving $\mathbf{5}$ as the sole product in quantitative yields. In particular, HAA is observed with cyclohexene (BDE: 87 $\mathrm{kcal} / \mathrm{mol}$ ) and fully saturated cyclohexane (BDE: $99 \mathrm{kcal} / \mathrm{mol}$ ) (Figure 2a), yielding benzene in both cases as confirmed by NMR spectroscopy and GC/MS analyses (Figures S30 S33). ${ }^{39}$ Interestingly, performing the reaction in the presence of excess cyclooctane (BDE: $95 \mathrm{kcal} / \mathrm{mol})^{39}$ generates 1,5cyclooctadiene exclusively (Figures S34 - S36).

The reactivity of our system towards cyclohexane afforded us the opportunity to easily examine the KIE upon switching from $\mathrm{C}_{6} \mathrm{H}_{12}$ to $\mathrm{C}_{6} \mathrm{D}_{12}$ in the reaction mixtures. Photolysis of $\mathbf{4 a}$ $(100 \mu \mathrm{M})$ in $\mathrm{C}_{6} \mathrm{H}_{6} /$ py $(10: 1)$ in the presence of 100 equiv of cyclohexane was followed by UV-vis absorption spectroscopy (Figure 2b). As seen from the rate plot presented in Figure 2c, there is a clear difference in rate with a KIE $=2.5 \pm 0.1$. This value is within the $\mathrm{KIE}$ range established for the related $\mathrm{Fe}=\mathrm{O}$ mediated HAA reactions $(\mathrm{KIE}=2.5-5.7)^{40}$ and in complete accordance with the HAA chemistry observed for the $\mathrm{Co}=\mathrm{O}$ complex $[(\mathrm{N} 4 \mathrm{Py}) \mathrm{Co}(\mathrm{O})]^{2+}(\mathrm{N} 4 \mathrm{Py}=N, N$-bis(2-pyridylmethyl)$N$-bis(2-pyridyl)methylamine $)(\mathrm{KIE}=2.1 \pm 0.1) .{ }^{41}$ This reaction can be performed on a preparative scale, giving the isotopomers 5-H and 5-D that exhibit imido N-H and N-D stretching frequencies in the infrared spectrum at $3424 \mathrm{~cm}^{-1}$ and 2257 $\mathrm{cm}^{-1}$ (Figure $\mathrm{S} 17$ ), respectively, within the expected isotopic mass shift range of ca. $2500 \mathrm{~cm}^{-1}$.

Understanding the reactivity of molecular metal nitrides towards hydrogen is very important for providing chemical insights into the formation of ammonia through the HaberBosch process. ${ }^{42}$ Despite this, only a few examples of nitride 


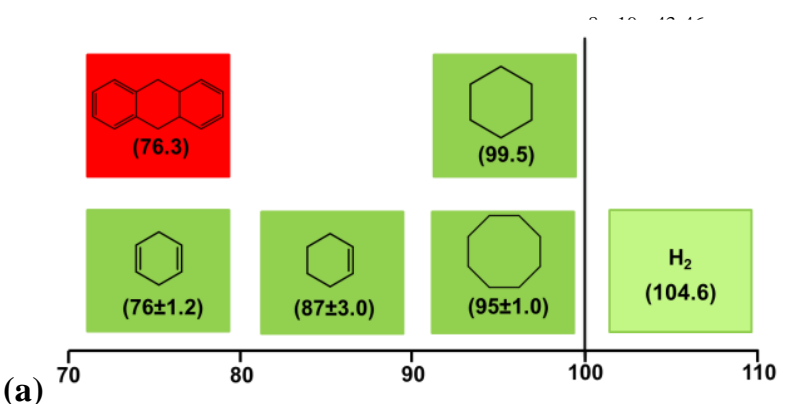

(a)

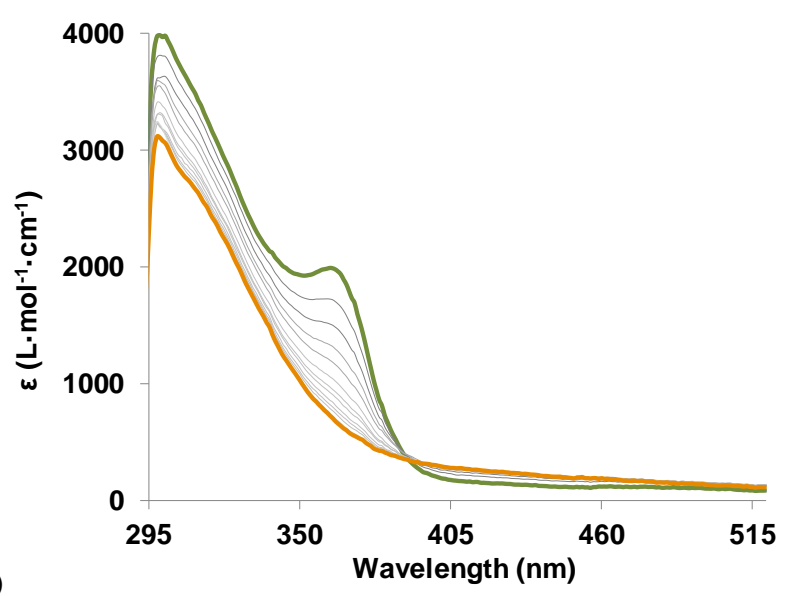

(b)

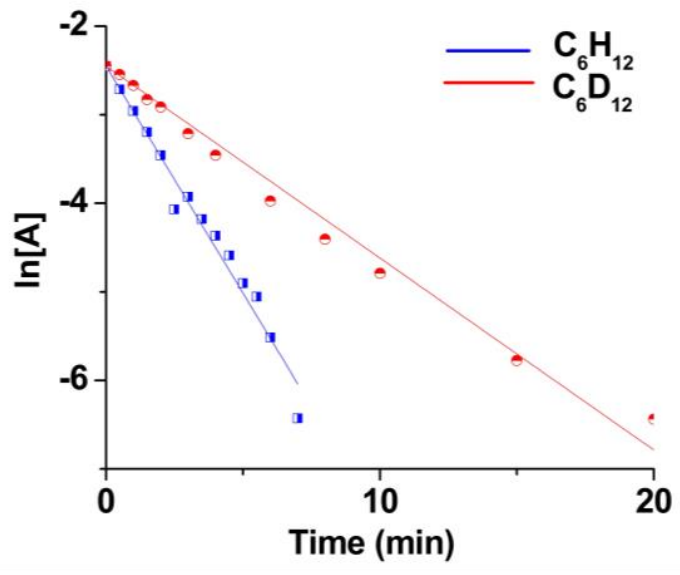

(c)

Figure 2. (a) Substrate screening for the HAA chemistry of $\mathbf{1}$ and respective $\mathrm{C}-\mathrm{H}$ BDEs. (b) UV-vis spectra of the photoconversion of $\mathbf{4 a}$ (green) to $\mathbf{5}$ (orange) in $\mathrm{C}_{6} \mathrm{H}_{6} /$ py solution in the presence of excess CHD. (c) KIE rate plot of the photolysis of $\mathbf{4 a}$ in $\mathrm{C}_{6} \mathrm{H}_{6} /$ py (10:1) in the presence of 100 equiv of $\mathrm{C}_{6} \mathrm{H}_{12}$ (blue) and $\mathrm{C}_{6} \mathrm{D}_{12}$ (red).

Whether 6 forms from the heterolytic or homolytic cleavage of $\mathrm{H}_{2}$ is not known at this time, though the preference in our system for HAA of strong $\mathrm{C}-\mathrm{H}$ bonds suggests the latter. Conducting the experiment in $\mathrm{C}_{6} \mathrm{D}_{6} / \mathrm{py}-d_{5}$ with $\mathrm{H}_{2}$ exclusively gives 6-H with a $\mathrm{N}-\mathrm{H}$ stretching frequency appearing at 3422 $\mathrm{cm}^{-1}$ (Figure S18), indicating no HAA reactivity with the solvent. Moreover, photolyzing $\mathrm{C}_{6} \mathrm{D}_{6} /$ py- $d_{5}$ solutions of 5 under $\mathrm{H}_{2}$ (150 psi) gradually gives way to $\mathbf{6}$, suggesting the formation of the bis(imido) occurs stepwise.

Computed Geometry and Electronic Structure. To scrutinize the electronic structure of $\mathbf{1}$, we turned to density functional theory (DFT). Using a non-truncated model of $\mathbf{1}$, in an anionic form without the $\left[\mathrm{Na}(\mathrm{THF})_{4}\right]^{+}$counterion, the empirical X-ray structure was remarkably reproduced by dispersioncorrected DFT calculations in the quintet spin state (see Supporting Information for details). We used quasi-restricted orbitals (QROs) (Figure 3) to rationalize and characterize the electronic structure of $\mathbf{1}$. QROs express unrestricted wavefunctions (with different $\alpha$ and $\beta$ orbital subsets) through the intuitive conceptual picture of the restricted open-shell (RO) solution with doubly and singly occupied orbitals (i.e. through identical $\alpha$ and $\beta$ spatial orbitals). 


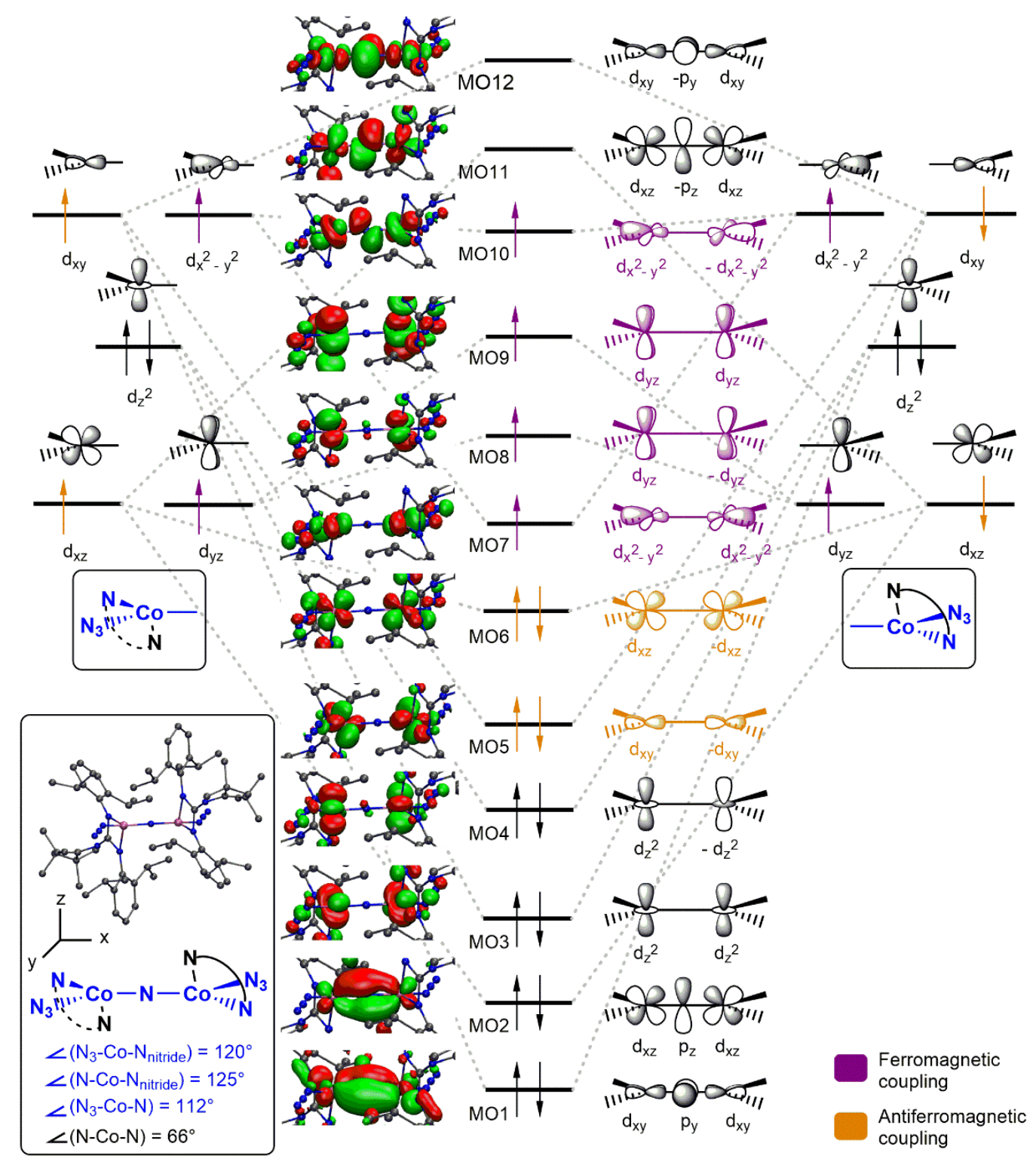

Figure 3. Molecular orbital diagram of the Co-N-Co core of $\mathbf{1}$.

According to the features of the revealed molecular QROs, 1 can be formally described as possessing two, high-spin $\mathrm{Co}$ (III) centers exhibiting both antiferromagnetic and weak ferromagnetic coupling through two two-electron interactions each (Figure 3). The formal partition of these delocalized MOs to individual cobalt contributions gives four half-filled $\mathrm{d}$ orbitals, $\mathrm{d}_{\mathrm{xz}}, \mathrm{d}_{\mathrm{yz}}, \mathrm{d}_{\mathrm{xy}}$, and $\mathrm{d}_{\mathrm{x} 2-\mathrm{y} 2}$ with a doubly occupied $\mathrm{d}_{\mathrm{z} 2^{-}}$ orbital at each metal. At each cobalt, two of the metal-centered radicals couple antiferromagnetically in the p-subspace mediated by the bridging nitride, whereas the couplings of unpaired electrons with local s- and d-symmetries through the nitrogen are limited and, accordingly, remain weak and ferromagnetic in nature. This gives an overall quintet spin-state, which agrees with the measured effective magnetic moment of 3.60 $\mu_{\mathrm{B}}$, substantiating the model and chosen analysis method. A similar magnetic phenomenon has been documented in the case of $\left[(\mathrm{NNNO}) \mathrm{Ni}\left(\mu-\mathrm{N}_{3}\right)\right]_{2}$, which also exhibits both antiferromagnetic and ferromagnetic coupling interactions. ${ }^{47}$

To better envisage the bonding interactions in $\mathbf{1}$, a simplified substructure of the "( ${ }^{\mathrm{ket}}$ guan $) \operatorname{Co}(\mu-\mathrm{N})\left(\mathrm{N}_{3}\right)$ " unit can be defined by the cobalt center, its azide group, the bridging $\mathrm{N}_{\mathrm{ni}-}$ tride, and one of the nitrogen contact atoms from each [ $\left.{ }^{\mathrm{ket}} \mathrm{guan}\right]^{-}$ ligand, giving an $\mathrm{ML}_{3}$ structural approximation for each metal which is highlighted in blue in Figure 3 (see inset). This yields a planar arrangement where the ligand atoms are separated by nearly $120^{\circ}$, affording a $\mathrm{D}_{3 \mathrm{~h}}$ symmetry approximation for each cobalt fragment with the out-of-plane nitrogen atom of the ${ }^{\text {ket }}$ guan $]^{-}$ligand acting as an asymmetric axial perturbation on the idealized electronic structure at the metal. Through this perspective, the d-orbital arrangement represents the most ideal orientation for the schematic representation of the cobaltnitride and cobalt-cobalt interactions.

Accordingly, the in-plane $d_{x y}$ orbitals are perfectly oriented on both sides to form an appreciable three-center, two-electron overlap integral with the $\mathrm{p}_{\mathrm{y}}$ orbital of the $\mathrm{N}_{\text {nitride }}$ atom as seen in the molecular orbital picture, MO1, in Figure 3. An almost identical three-center $\pi$-interaction (MO2) evolves in the perpendicular xz-plane through the $\operatorname{Co}\left(\mathrm{d}_{\mathrm{xz}}\right)+\mathrm{N}\left(\mathrm{p}_{\mathrm{z}}\right)+\mathrm{Co}\left(\mathrm{d}_{\mathrm{xz}}\right)$ atomic orbital combination. Both of these molecular orbitals formally

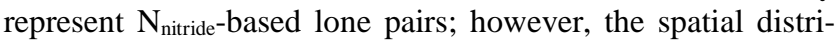


butions clearly expose delocalization to the metals resulting in the formation of $\pi$-type bonding interactions of covalent character. The two other lone pairs of the formally $\mathrm{N}^{-3}$ bridge are represented by low lying orbitals with $\mathrm{N}\left(\mathrm{p}_{\mathrm{x}}\right)$ and $\mathrm{N}(\mathrm{s})$ character (not shown in Figure 3).

These three-center, two-electron combinations give way to the $d_{x y}-d_{x y}(M O 5)$ and $d_{x z}-d_{x z}$ (MO6), antisymmetric nonbonding orbital configurations (Figure 3), leading to antiferromagnetic coupling of the metal-centered electrons in nondegenerate molecular orbitals. In contrast, the symmetric and antisymmetric $\sigma$ - and $\delta$-symmetry oriented d-orbitals, $\mathrm{d}_{\mathrm{x} 2-\mathrm{y} 2^{-}}$ $\mathrm{d}_{\mathrm{x} 2-\mathrm{y} 2}$ and $\mathrm{d}_{\mathrm{yz}}-\mathrm{d}_{\mathrm{yz}}$, respectively, appear as quasi-degenerate orbitals (MO7 - MO10) with each hosting one electron according to Hund's maximum multiplicity rule.

Owing to the strong delocalization of the nitride lone-pairs to the metals (MO1 and MO2), the central Co-N interactions have a notable $\pi$-bond character in addition to the dative $\sigma$ bond. Accordingly, the electronic structure of 1 can be best represented by the $\mathrm{Co}^{\mathrm{III}}=\mathrm{N}=\mathrm{Co}^{\mathrm{III}}$ canonical form, with the data indicating no radical character at the nitride atom. Mayer bond orders of 1.33 calculated for the $\mathrm{Co}-\mathrm{N}$ interactions support this notion. The spin density value of 1.5 at each cobalt conforms also to the deduced electronic structure with partial antiferromagnetic coupling. As the unpaired electrons occupy $\sigma$ - and $\delta$ symmetry metal orbitals that cannot mix with the nitrogen's $\pi$ symmetry $\mathrm{p}_{\mathrm{x}}$ and $\mathrm{p}_{\mathrm{z}}$ atomic orbitals, the radical character cannot delocalize to the bridging nitrogen, which is reflected by the negligible atom-condensed spin density value of 0.1 at the nitrogen.

The lowest-lying unoccupied molecular orbitals, MO11 and MO12, correspond to the antibonding combinations of the $\mathrm{Co}=\mathrm{N}=\mathrm{Co} \pi$-interactions and have notable amplitude at the central nitrogen due to the covalent nature of the Co-N $\pi$ bonds. In comparison, the reported spin density distribution of the related dimer $(\mathrm{PNN}) \mathrm{Rh}(\mathrm{N} \cdot) \mathrm{Rh}(\mathrm{PNN})^{15}$ closely resembles the out of plane antibonding combination of 1, MO11, with one electron occupancy of this orbital in the dirhodium nitride case. As a matter of fact, this additional electron within the $\left\{\mathrm{Rh}_{2} \mathrm{~N}\right\}^{13}$ core of $(\mathrm{PNN}) \mathrm{Rh}(\mathrm{N} \cdot) \mathrm{Rh}(\mathrm{PNN})$ embodies the most significant formal difference between its electronic structure and the $\left\{\mathrm{Co}_{2} \mathrm{~N}\right\}^{12}$ core of $\mathbf{1}$, thus giving way to the observed nitridyl radical character in $(\mathrm{PNN}) \mathrm{Rh}(\mathrm{N} \cdot) \mathrm{Rh}(\mathrm{PNN})$ that is absent in $\mathbf{1}$.

\section{CONCLUSION}

In conclusion, while late metal complexes of the type $\mathrm{M}=\mathrm{E} / \mathrm{M} \equiv \mathrm{E}$ can be difficult to access and stabilize owing to "oxo wall" considerations, we show here that surrogates for such chemistry can be obtained through systems of the type $\mathrm{M}=\mathrm{E}=\mathrm{M}$. In this case, we demonstrate that the first example of a bimetallic cobalt nitride, compound $\mathbf{1}$, is easily accessed through photolysis of a guanidinate cobalt-azide precursor. According to DFT calculations, conforming also to experimental observations, 1 possesses two high-spin cobalt(III) centers coupled through a formal $\mathrm{Co}^{\mathrm{III}}=\mathrm{N}=\mathrm{Co}^{\mathrm{III}}$ core with covalent $\mathrm{Co}-\mathrm{N} \pi$-bonds. The pseudo-planar arrangement about the $\mathrm{Co}^{\mathrm{III}}=\mathrm{N}=\mathrm{Co}^{\mathrm{III}}$ unit facilitates the antiferromagnetic coupling of $\pi$-symmetry metal-centered radicals (two at each Co) across the bridging nitride, whereas the inefficient throughspace interaction of $\sigma$ - and $\delta$-symmetry d-orbitals leads to the weak ferromagnetic coupling of the corresponding unpaired electrons (also two at each $\mathrm{Co}$ ), eventuating in an $\mathrm{S}=2$, quintet spin-state of $\mathbf{1}$. The geometry and electron count of the cobalt centers avoids population of $\mathrm{Co}-\mathrm{N} \pi^{*}$-orbitals, thereby avoiding radical character at the $\mathrm{N}$-atom. Consequently, $\mathbf{1}$ is stable in solution and as a solid. However, its $\mathrm{N}$-atom reactivity is accessible through addition of pyridine, triggering HAA chemistry to give the bridged imido 5. Impressively, this HAA reactivity extends to strong $\mathrm{C}-\mathrm{H}$ bonds such as those found in cyclohexane $(\mathrm{BDE} \sim 100 \mathrm{kcal} / \mathrm{mol}$ ). Moreover, this chemistry can be further extended to include $\mathrm{H}_{2}$, leading to a rare example of hydrogen activation by a molecular metal nitride to generate the bis(imido) 6. At present, investigations are underway to understand the observed $\mathrm{H}_{2}$ activation chemistry while working to apply our synthetic strategy to other late metal systems.

\section{ASSOCIATED CONTENT}

\section{Supporting Information}

The Supporting Information is available free of charge on the ACS Publications website. Crystallographic details (CIF) and the supporting Information is available free of charge on the ACS Publication Website at DOI:

Experimental procedures, spectral data for all the complexes, magnetic data and computational details (PDF)

\section{AUTHOR INFORMATION}

\author{
Corresponding Authors \\ *asfortier@utep.edu, \\ *balazs.pinter@usm.cl \\ ORCID
}

Debabrata Sengupta: 0000-0001-7212-3761

Ram Seshadri: 0000-0001-5858-4027

Balazs Pinter: 0000-0002-0051-5229

Skye Fortier: 0000-0002-0502-5229

Notes

The authors declare no competing financial interests.

\section{ACKNOWLEDGMENT}

We are grateful to the NSF (CHE-1664938 and DMR-1827745; S.F.) and the Welch Foundation (AH-1922-20170325; S.F) for financial support of this work. S.F. is an Alfred P. Sloan Foundation research fellow and is thankful for their support. We also wish to acknowledge the NSF-MRI program (CHE-1827875) for providing funding for the purchase of an X-ray diffractometer. Magnetic measurements were performed at the shared experimental facilities of the NSF Materials Research Science and Engineering Center (MRSEC) at UC Santa Barbara (DMR 1720256). The UCSB MRSEC is a member of the NSF-supported Materials Research Facilities Network (www.mrfn.org).

\section{REFERENCES}

(1) Hohenberger, J.; Ray, K.; Meyer, K., The biology and chemistry of high-valent iron-oxo and iron-nitrido complexes. Nat. Commun. 2012, 3, 720.

(2) Handbook of Metathesis. Wiley-VCH Verlag $\mathrm{GmbH} \& \mathrm{Co}$ : 2015.

(3) Schrock, R. R., Multiple metal-carbon bonds for catalytic metathesis reactions (Nobel Lecture). Angew. Chem. Int. Ed. 2006, $45,3748-3759$ 
(4) Smith, J. M., Reactive transition metal nitride complexes. Prog. Inorg. Chem. 2014, 58, 417-470.

(5) Gray, H. B.; Winkler, J. R., Living with Oxygen. Acc. Chem. Res. 2018, 51, 1850-1857.

(6) Berry, J. F., Terminal nitrido and imido complexes of the late transition metals. Comments Inorg. Chem. 2009, 30, 28-66.

(7) Hartmann, N. J.; Wu, G.; Hayton, T. W., Synthesis of a "Masked" Terminal Nickel(II) Sulfide by Reductive Deprotection and its Reaction with Nitrous Oxide. Angew. Chem. Int. Ed. 2015, 54, 14956-14959.

(8) Scheibel, M. G.; Askevold, B.; Heinemann, F. W.; Reijerse, E. J.; de Bruin, B.; Schneider, S., Closed-shell and open-shell squareplanar iridium nitrido complexes. Nat. Chem. 2012, 4, 552-558.

(9) O'Halloran, K. P.; Zhao, C. C.; Ando, N. S.; Schultz, A. J.; Koetzle, T. F.; Piccoli, P. M. B.; Hedman, B.; Hodgson, K. O.; Bobyr, E.; Kirk, M. L.; Knottenbelt, S.; Depperman, E. C.; Stein, B.; Anderson, T. M.; Cao, R.; Geletii, Y. V.; Hardcastle, K. I.; Musaev, D. G.; Neiwert, W. A.; Fang, X. K.; Morokuma, K.; Wu, S. X.; Kogerler, P.; Hill, C. L., Revisiting the Polyoxometalate-Based LateTransition-Metal-Oxo Complexes: The "Oxo Wall" Stands. Inorg. Chem. 2012, 51, 7025-7031.

(10) Winkler, J. R.; Gray, H. B., Electronic structures of oxo-metal ions. Struct. Bonding (Berlin, Ger.) 2012, 142 (Molecular Electronic Structures of Transition Metal Complexes I), 17-28.

(11) Schoffel, J.; Susnjar, N.; Nuckel, S.; Sieh, D.; Burger, P., 4d vs. 5d-Reactivity and Fate of Terminal Nitrido Complexes of Rhodium and Iridium. Eur. J. Inorg. Chem. 2010, 4911-4915.

(12) Rebreyend, C.; Mouarrawis, V.; Siegler, M. A.; van der Vlugt, J. I.; de Bruin, B., Steric Protection of Rhodium-Nitridyl Radical Species. Eur. J. Inorg. Chem. 2019, 4249-4255.

(13) Saouma, C. T.; Peters, J. C., M E and M=E complexes of iron and cobalt that emphasize three-fold symmetry (E O, N, NR). Coord. Chem. Rev. 2011, 255, 920-937.

(14) Hay-Motherwell, R. S.; Wilkinson, G.; Hussain-Bates, B.; Hursthouse, M. B., Synthesis and $\mathrm{x}$-ray crystal structure of oxotrimesityliridium(V). Polyhedron 1993, 12, 2009-12.

(15) Gloaguen, Y.; Rebreyend, C.; Lutz, M.; Kumar, P.; Huber, M.; van der Vlugt, J. I.; Schneider, S.; de Bruin, B., An Isolated Nitridyl Radical-Bridged $\{\mathrm{Rh}(\mathrm{N}.) \mathrm{Rh}\}$ Complex. Angew. Chem. Int. Ed. 2014, 53, 6814-6818.

(16) Scheibel, M. G.; Wu, Y.; Stueckl, A. C.; Krause, L.; Carl, E.; Stalke, D.; de Bruin, B.; Schneider, S., Synthesis and Reactivity of a Transient, Terminal Nitrido Complex of Rhodium. J. Am. Chem. Soc. 2013, 135, 17719-17722.

(17) Angersbach-Bludau, F.; Schulz, C.; Schoeffel, J.; Burger, P., Syntheses and electronic structures of $\mu$-nitrido bridged pyridine, diimine iridium complexes. Chem. Commun. (Cambridge, U. K.) 2014, 50, 8735-8738.

(18) Schoeffel, J.; Rogachev, A. Y.; DeBeer George, S.; Burger, P., Isolation and Hydrogenation of a Complex with a Terminal IridiumNitrido Bond. Angew. Chem. Int. Ed. 2009, 48, 4734-4738.

(19) Schoffel, J.; Rogachev, A. Y.; George, S. D.; Burger, P., Isolation and Hydrogenation of a Complex with a Terminal IridiumNitrido Bond. Angew. Chem. Int. Ed. 2009, 48, 4734-4738.

(20) Sieh, D.; Schlimm, M.; Andernach, L.; Angersbach, F.; Nuckel, S.; Schoffel, J.; Susnjar, N.; Burger, P., Metal-Ligand Electron Transfer in 4d and 5d Group 9 Transition Metal Complexes with Pyridine, Diimine Ligands. Eur. J. Inorg. Chem. 2012, 444-462.

(21) Goetz, M. K.; Hill, E. A.; Filatov, A. S.; Anderson, J. S., Isolation of a Terminal Co(III)-Oxo Complex. J. Am. Chem. Soc. 2018, 140, 13176-13180.

(22) Hojilla Atienza, C. C.; Bowman, A. C.; Lobkovsky, E.; Chirik, P. J., Photolysis and Thermolysis of Bis(imino)pyridine Cobalt Azides: C-H Activation from Putative Cobalt Nitrido Complexes. J. Am. Chem. Soc. 2010, 132 (46), 16343-16345.

(23) Zolnhofer, E. M.; Kaess, M.; Khusniyarov, M. M.; Heinemann, F. W.; Maron, L.; van Gastel, M.; Bill, E.; Meyer, K., An Intermediate Cobalt(IV) Nitrido Complex and its N-Migratory Insertion Product. J. Am. Chem. Soc. 2014, 136, 15072-15078.

(24) Pfaff, F. F.; Kundu, S.; Risch, M.; Pandian, S.; Heims, F.; Pryjomska-Ray, I.; Haack, P.; Metzinger, R.; Bill, E.; Dau, H.;
Comba, P.; Ray, K., An Oxocobalt(IV) Complex Stabilized by Lewis Acid Interactions with Scandium(III) Ions. Angew. Chem. Int. Ed. 2011, 50, 1711-1715.

(25) Cui, P.; Wang, Q.; McCollom, S. P.; Manor, B. C.; Carroll, P. J.; Tomson, N. C., Ring-Size-Modulated Reactivity of Putative Dicobalt-Bridging Nitrides: C-H Activation versus Phosphinimide Formation. Angew. Chem. Int. Ed. 2017, 56, 15979-15983.

(26) Maity, A. K.; Metta-Magana, A. J.; Fortier, S., Donor Properties of a New Class of Guanidinate Ligands Possessing Ketimine Backbones: A Comparative Study Using Iron. Inorg. Chem. 2015, 54, 10030-10041.

(27) Maity, A. K.; Murillo, J.; Metta-Magana, A. J.; Pinter, B.; Fortier, S., A Terminal Iron(IV) Nitride Supported by a Super Bulky Guanidinate Ligand and Examination of Its Electronic Structure and Reactivity. J. Am. Chem. Soc. 2017, 139, 15691-15700.

(28) Fortier, S.; Le Roy, J. J.; Chen, C. H.; Vieru, V.; Murugesu, M.; Chibotaru, L. F.; Mindiola, D. J.; Caulton, K. G., A Dinuclear Cobalt Complex Featuring Unprecedented Anodic and Cathodic Redox Switches for Single-Molecule Magnet Activity. J. Am. Chem. Soc. 2013, 135, 14670-14678.

(29) Fortier, S.; Moral, O. G. D.; Chen, C. H.; Pink, M.; Le Roy, J. J.; Murugesu, M.; Mindiola, D. J.; Caulton, K. G., Probing the redox non-innocence of dinuclear, three-coordinate $\mathrm{Co}$ (II) nindigo complexes: not simply beta-diketiminate variants. Chem. Commun. 2012, 48, 11082-11084.

(30) Jones, C.; Schulten, C.; Rose, R. P.; Stasch, A.; Aldridge, S.; Woodul, W. D.; Murray, K. S.; Moubaraki, B.; Brynda, M.; La Macchia, G.; Gagliardi, L., Amidinato- and Guanidinato-Cobalt(I) Complexes: Characterization of Exceptionally Short Co-Co Interactions. Angew. Chem. Int. Ed. 2009, 48, 7406-7410.

(31) Tornieporthoetting, I. C.; Klapotke, T. M., Covalent Inorganic Azides. Angew. Chem. Int. Ed. 1995, 34, 511-520.

(32) Costa, M.; Della Pergola, R.; Fumagalli, A.; Laschi, F.; Losi, S.; Macchi, P.; Sironi, A.; Zanello, P., Mixed Co-Rh nitridoencapsulated carbonyl clusters. Synthesis, solid-state structure, and electrochemical/EPR characterization of the anions $\left[\mathrm{Co}_{10} \mathrm{Rh}(\mathrm{N})_{2}(\mathrm{CO})_{21}\right]^{3-}, \quad\left[\mathrm{Co}_{10} \mathrm{Rh}_{2}(\mathrm{~N}) 2(\mathrm{CO})_{24}\right]^{2-}, \quad$ and $\left[\mathrm{Co}_{11} \mathrm{Rh}(\mathrm{N})_{2}(\mathrm{CO})_{24}\right]^{2-}$. Inorg. Chem. 2007, 46, 552-560.

(33) Hu, X. L.; Meyer, K., Terminal cobalt(III) imido complexes supported by tris(carbene) ligands: Imido insertion into the cobaltcarbene bond. J. Am. Chem. Soc. 2004, 126, 16322-16323.

(34) Gloaguen, Y.; Rebreyend, C.; Lutz, M.; Kumar, P.; Huber, M.; van der Vlugt, J. I.; Schneider, S.; de Bruin, B., An Isolated Nitridyl Radical-Bridged $\{\mathrm{Rh}(\mathrm{N}$-center dot $) \mathrm{Rh}\}$ Complex. Angew. Chem. Int. Ed. 2014, 53, 6814-6818.

(35) Baek, Y.; Betley, T. A., Catalytic C-H Amination Mediated by Dipyrrin Cobalt Imidos. J. Am. Chem. Soc. 2019, 141, 7797-7806.

(36) Man, W. L.; Lam, W. W. Y.; Kwong, H. K.; Yiu, S. M.; Lau, T. C., Ligand-Accelerated Activation of Strong C-H Bonds of Alkanes by a (Salen)ruthenium(VI)-Nitrido Complex. Angew. Chem. Int. Ed. 2012, 51, 9101-9104.

(37) Marsh, R. E.; Thewalt, U., Structure of racemic .mu.-amido.mu.-hydroxy-bis[bis(ethylenediamine)cobalt(III)] tetranitrate hydrate. Inorg. Chem. 1971, 10, 1789-1795.

(38) Dai, X. L.; Kapoor, P.; Warren, T. H., $\left[\mathrm{Me}_{2} \mathrm{NN}\right] \mathrm{Co}(\mathrm{eta}(6)-$ toluene): $\mathrm{O}=\mathrm{O}, \mathrm{N}=\mathrm{N}$, and $\mathrm{O}=\mathrm{N}$ bond cleavage provides, betadiketiminato cobalt mu-oxo and imido complexes. J. Am. Chem. Soc. 2004, 126, 4798-4799.

(39) Xue, X.-S.; Ji, P.; Zhou, B.; Cheng, J.-P., The Essential Role of Bond Energetics in C-H Activation/Functionalization. Chem. Rev. (Washington, DC, U. S.) 2017, 117, 8622-8648.

(40) Andris, E.; Navratil, R.; Jasik, J.; Thibault, T.; Srnec, M.; Costas, M.; Roithova, J., Chasing the Evasive $\mathrm{Fe}=\mathrm{O}$ Stretch and the Spin State of the Iron(IV)-Oxo Complexes by Photodissociation Spectroscopy. J. Am. Chem. Soc. 2017, 139, 2757-2765.

(41) Andris, E.; Navratil, R.; Jasik, J.; Srnec, M.; Rodriguez, M.; Costas, M.; Roithova, J., M-O Bonding Beyond the Oxo Wall: Spectroscopy and Reactivity of Cobalt(III)-Oxyl and Cobalt(III)-Oxo Complexes. Angew. Chem. Int. Ed. 2019, 58, 9619-9624.

(42) Holscher, M.; Leitner, W., Catalytic NH3 Synthesis using N2/H-2 at Molecular Transition Metal Complexes: Concepts for Lead 
Structure Determination using Computational Chemistry. Chem-Eur.

J. 2017, 23, 11992-12003.

(43) Brown, S. D.; Mehn, M. P.; Peters, J. C., Heterolytic H-2 activation mediated by low-coordinate $\mathrm{L}_{3} \mathrm{Fe}-(\mathrm{mu}-\mathrm{N})-\mathrm{FeL}_{3}$ complexes to generate $\mathrm{Fe}(\mathrm{mu}-\mathrm{NH})(\mathrm{mu}-\mathrm{H}) \mathrm{Fe}$ species. J. Am. Chem. Soc. 2005, 127, 13146-13147.

(44) Askevold, B.; Nieto, J. T.; Tussupbayev, S.; Diefenbach, M.; Herdtweck, E.; Holthausen, M. C.; Schneider, S., Ammonia formation by metal-ligand cooperative hydrogenolysis of a nitrido ligand. Nat. Chem. 2011, 3, 532-537.

(45) Schendzielorz, F. S.; Finger, M.; Volkmann, C.; Wurtele, C.; Schneider, S., A Terminal Osmium(IV) Nitride: Ammonia Formation and Ambiphilic Reactivity. Angew. Chem. Int. Ed. 2016, 55, $11417-$ 11420.

(46) Falcone, M.; Poon, L. N.; Tirani, F. F.; Mazzanti, M., Reversible Dihydrogen Activation and Hydride Transfer by a Uranium Nitride Complex. Angew. Chem. Int. Ed. 2018, 57, $3697-$ 3700 .

(47) Sarkar, S.; Datta, A.; Mondal, A.; Chopra, D.; Ribas, J.; Rajak, K. K.; Sairam, S. M.; Pati, S. K., Competing Magnetic Interactions in a Dinuclear $\mathrm{Ni}(\mathrm{II})$ Complex: Antiferromagnetic O$\mathrm{H} \cdots \mathrm{O}$ Moiety and Ferromagnetic N3- Ligand. J. Phys. Chem. B 2006, $110,12-15$ 